\title{
Logic buồn của người Hy Lạp
}

\author{
Tam Nguyên Media
}

January 21, 2012

https://tamnguyen.vn/Logic-buon-cua-nguoi-Hy-Lap/ 


\section{TAM NGUYÊN MEDIA}

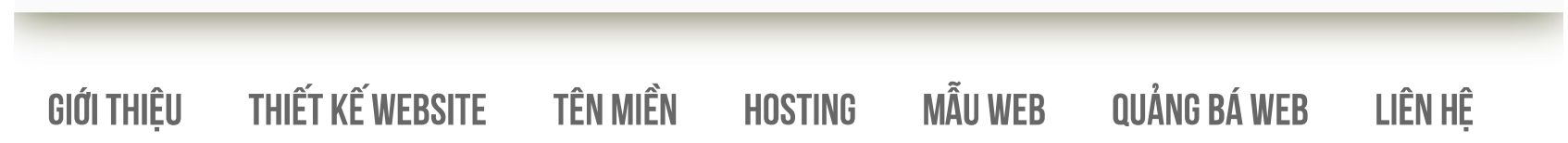

HUỨNG DẪN

\section{Nghiên cứu tình huống}

Trang chủ » Thông tin » Kiến thức kinh doanh » Nghiên cứu tình huống

\section{Logic buồn của người Hy Lạp}

Trong cuốn sách "Văn minh làm giàu và nguồn gốc của cải”, tiến sĩ Vương Quân Hoàng kể lại câu chuyện một người ト hỏi ông tại sao người Hy Lạp cổ đại thông minh? và anh ta giải thích: "Thời đó người Hy Lạp thông minh là vì người ta nı

- Trong cuốn sách "Văn minh làm giàu và nguồn gốc của cải”, tiến sĩ Vương Quân Hoàng kể lại câu chuyện một người Hy Lạp hỏi sao người Hy Lạp cổ đại thông minh? và anh ta giải thích: "Thời đó người Hy Lạp thông minh là vì người ta no đủ. Người Hy Lạp xL thừa của cải trước tiên nhờ canh tác nông nghiệp, nhưng đặc biệt quan trọng và trên hết là nhờ thương mại trên nông sản. Tích lũy sự giàu có từ lợi nhuận vượt trội của hoạt động thương mại quốc tế, người ta phân công lao động. Sau đó, xã hội phân hóa những có khả năng trí tuệ vượt trội được đãi ngộ để suy nghĩ và xây dựng hệ thống kiến thức. Họ sớm coi trọng cả kinh doanh thương mạ kiến thức được hệ thống hóa của con người. Cả giá trị tiền tệ và giá trị văn hóa được thừa nhận như những mục tiêu theo đuổi tới c đích văn minh thịnh vượng"(*).

Cuộc khủng hoảng nợ công của Hy Lạp ngày hôm nay đưa đến hai tiền đề từ giải thích trên:

Thứ nhất, Hy Lạp đã quên bài học quá khứ, để có những người thông minh thì phải tích lũy chứ không phải vay nợ. Người Hy Lạk thu được lợi nhuận vượt trội từ hoạt động thương mại quốc tế thì người Hy Lạp hiện đại thâm hụt cả trong thương mại quốc tế lẫn tiêu ngân sách. Ví dụ: Chính phủ Hy Lạp đã chi 12 tỷ euro (cao hơn tới 10 tỷ so với dự kiến) cho Olympic 2004 - kỳ thế vận hội đưc là hoành tráng nhất và cũng tốn kém nhất trong lịch sử - khiến ngân sách quốc gia năm 2004 thâm hụt tới 6,1\% (so với GDP) troṇ giới hạn mà khối EU cho phép là 3\%, xuất khẩu năm 2006 là 24,4 tỷ USD nhưng nhập khẩu lên đến 59,1 tỷ USD. Nợ công của Hy hiện lên tới 300 tỷ euro (113\% GDP năm 2009). Gần đây, người ta mới phát hiện ra Hy Lạp đã "báo cáo láo" các số liệu kinh tế để sớm gia nhập khối các nước sử dụng đồng euro. Đức, quốc gia đóng vai trò quan trọng trong việc cứu Hy Lạp đã chỉ trích sự chi ti hoang phí của Chính phủ Hy Lạp.

Thứ hai, được thừa hưởng từ nền văn minh rực rỡ thời cổ đại, người Hy Lạp cảm thấy mình phải được đối xử, đãi ngộ cho xứng । bậc tiền bối Platon, Aristotle, Archimedes hay Pythagoras. Hậu quả là nguồn thu từ gia sản do tiền nhân để lại không đủ nuôi nhu c ngày càng lớn của con cháu. Quỹ lương của khối dịch vụ công tại Hy Lạp đã tăng gấp đôi trong vòng 10 năm qua, chi cho phúc lợi cũng chiếm một tỷ trọng lớn. Khi đã quen với cuộc sống vương giả thì họ không thể chấp nhận việc hạ thấp mức sống, nhiều cuộc tình, đình công đã nổ ra nhằm phản đối chính sách "thắt lưng buộc bụng" của Chính phủ; người Hy Lạp cũng có thể đã rất bực tức niệm 100 năm Olympic hiện đại nhưng họ không được đăng cai, thay vào đó người ta xoa dịu người Hy Lạp bằng quyền đăng cai Oympic 2004, kết quả là người Hy Lạp đã tổ chức một Olympic ra trò! Bộ trưởng Bộ Kinh tế Đức Rainer Bruederle gọi Hy Lạp là "q gia sống nhờ vào các chương trình phúc lợi mà chẳng chú ý tới năng lực cạnh tranh của mình".

Theo phép tam đoạn luận mà tổ tiên của người Hy Lạp phát minh ra thì kết luận là con cháu của Platon, Aristotle sẽ phải bán các $r$ đảo cho nước ngoài hoặc trở thành nô bộc tài chính của IMF, EU. Bài học của người Hy Lạp là bài học của bất kỳ dân tộc nào, khĉ dân tộc ngu ngốc mãi mãi và cũng không có dân tộc thông minh mãi mãi. Nếu có một quá khứ rực rỡ thì hãy quên nó đi và nếu có thì hãy nhớ tích lũy!

(*): Văn minh làm giàu và nguồn gốc của cải, NXB Chính trị quốc gia, tr 212

\section{http://www.tamnguyen.vn - Chúc các bạn thành công !}


Thêm bình luận...

Plugin bình luận trên Facebook

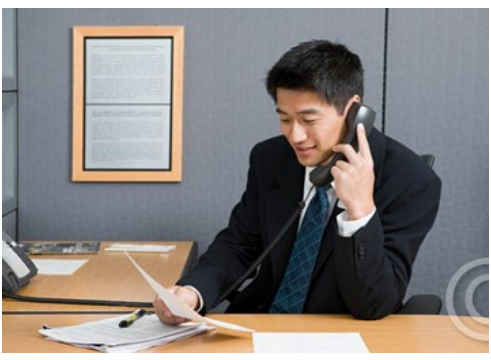

7 "MẸO VÀNG" ĐÉ CHÀO HÀNG THÀNH CÔNG QUA ĐIẸN THOẠI

Sự phát triển và bùng nổ công nghệ trong những năm gần đây tại Việt Nam đang mở ra một phương thức tiếp cận khách hàng mới: kỹ..

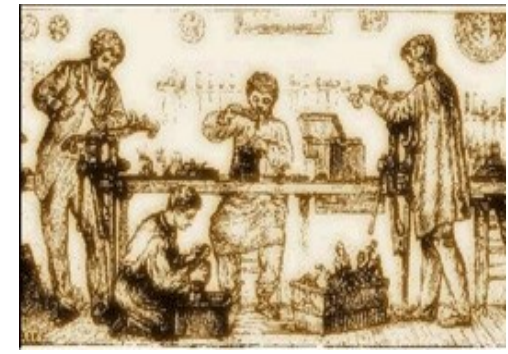

Sụp thay đổi phương thức quản lý trong nền kinh tế tri thức

"Con người là tài sản quan trọng nhất của chúng ta". Hành vi của các nhà lãnh đạo và quản lý nhân lực thời nay ở các tập đoàn kinh doanh thành đạt đã cho.

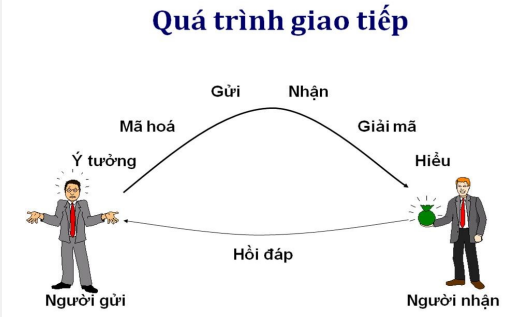

\section{PHƯO'NG PHÁP CHÀO HÀNG ĐAT} HIẸU QUẢ CAO

Nếu muốn giành được tình cảm của người nghe và biến họ thành khách hàng của mình, bạn phải biết thốt ra "những lời có cánh" để thu hút sự chú ý..

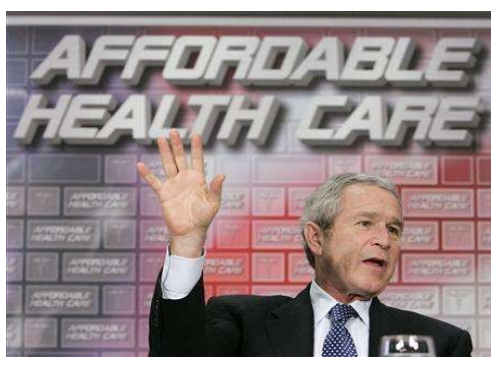

\section{Tại sao người giàu sống lâu hơn}

Có một lời lý giải hoàn toàn mới cho vấn đề tuổi thọ ngày một tăng cao của tầng lớp giàu có, và lý giải này lại khá trái..

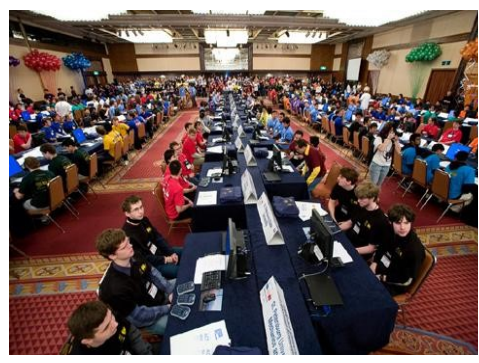

9 kỹ năng cần thiết cho nhân sự công nghệ thông tin năm 2012

Chiếc gọng kềm siết chặt chuyện tuyển dụng trong năm 2011 đã dần được nới lỏng. Các công ty công nghệ đang tìm kiếm nhân viên.

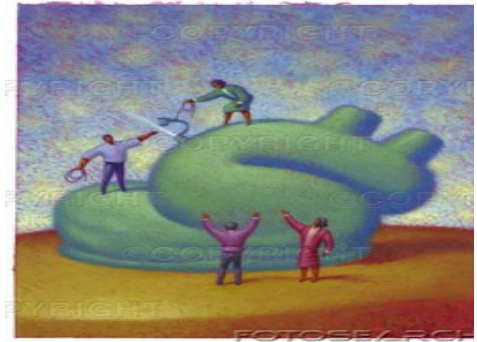

Tự sự của một người khởi nghiệp thất bại

Chẳng mấy ai đủ can đảm kể lại câu chuyện khởi nghiệp thất bại của chính mình, nhưng tác giả của bài báo dưới đây đã làm được điều đó. Sau lần thử thay đổi..

\section{THẾT KÊ WEBSITE}




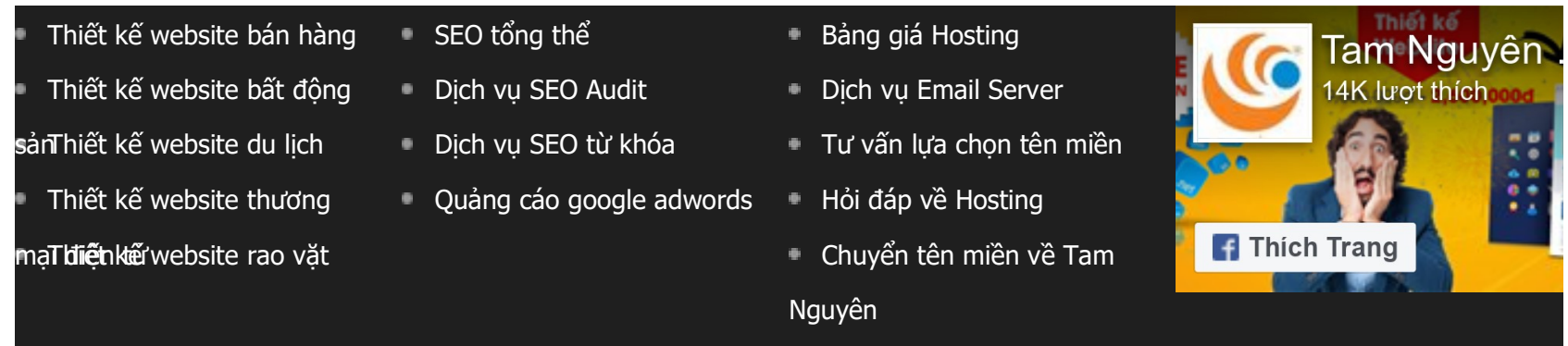

CÔNG TY TNHH CÔNG NGHẸ VÀ TRUYĖN THÔNG TAM NGUYÊN

Địa chỉ: Tầng 2A tòa $27 \mathrm{~A} 3$ Greenstars 234 Phạm Văn Đồng, Từ Liêm, Hà Nội

Điện thoại: 024.6666.1357 - Hotline: 0984966806

Email: lienhe@tamnguyen.vn

Quảng bá web | Thiết kế website | Vê chúng tôi | Liên hệ | Photoshop 
Tài liệu tham khảo:

[1] Đào Duy Anh. (1938). Việt Nam văn hóa sử cương. Quan Hải Tùng Thư, Huế (Imprimerie du Mirador).

[2] Vương Quân Hoàng. (2007). Văn minh làm giàu \& Nguồn gốc của cải. Nxb Chính trị Quốc gia, Hà Nội. 